\title{
Die Bestimmung der Lipaseaktivität unter Verwendung von Olivenöl als Substrat in neuer Form
}

\author{
Von R. Fried und J. Hoeflmayr \\ Aus den wissenschaftlichen Laboratorien der Firma Dr. H. Haury, Mïnchen
}

(Eingegangen am 21. September 1972/17. Januar 1973)

Die Bestimmung der Lipase (EC 3.1.1.3) im Serum unter Verwendung eines Olivenölsubstrats in neuer Form wird beschrieben. Das Substrat besteht aus Aerosil' ${ }^{1}$ ) als Träger, der in molekularer Schicht mit Olivenöl überzogen ist. Dieser Träger hat noch genügend Saugfähigkeit, um das zu untersuchende wäßrige Serum vollkommen aufzusaugen. Dadurch wird ein. Kontakt zwischen Ferment und Substrat auf möglichst großer Oberfläche hergestellt. Die freigesetzten Fettsäuren werden als chloroformlösliche Kupfersalze bestimmt.

\section{Determination of lipase activity using a new type olive oil substrate}

A method for the determination of serum lipase is described, in which a new type of olive oil substrate is employed. The substrate consists of Aerosil as a carrier, which is coated with a molecular film of olive oil. This carrier still has sufficient absorptive strength to absorb the aqueous serum specimen completely. Thus contact between the enzyme and the serum is established on as large a surface area as possible. The liberated fatty acids are determined as chloroform-soluble copper salts.

Die Vielzahl der Methoden zur Bestimmung der Lipaseaktivität beweist, daß bis heutè keine zufriedenstellende Methode für die Bestimmung dieses Pankreasenzyms, das Fette in Glycerin und Fettsäuren spaltet, gefunden wurde. Zwei Kriterien haben sich aber besonders zur Abgrenzung gegenüber pankreasunspezifischen Esterasen abgezeichnet. Einmal wird die Pankreaslipase durch cholsaure Salze aktiviert, zum anderen findet die Enzymreaktion an der Grenzfläche zwischen der wäßrigen Enzymlösung und dem öligen Medium hochmolekularer Fettsäureester statt; Glycerinester mit kurzkettigen Fettsäuren (z. B. Tributyrin) werden auch von unspezifischen Esterasen gespalten $(1,2)$.

Als Substrat wird heute vorzugsweise Olivenöl oder ein anderer Glycerinester von Fettsäuren mit mehr als 10 Kohlenstoffatomen verwendet. Die Aktivität des Enzyms wird anhand der freigesetzten Fettsäuren nachgewiesen. Diese werden entweder titriert oder als chloroformlösliche Kupfersalze photometrisch gemessen $(3, \dot{4}, 5)$. Wir haben uns aus nachstehend dargestellten Gründen für die photometrische Messung entschieden, bei der Fettsäuren mit einer Kettenlänge unter 10 Kohlenstoffatomen nicht erfaßt werden (5).

$\mathrm{Da}$ die Reaktion nur an der Grenzfläche zwischen öliger und wäßriger Phase stattfindet, muß das Olivenöl in Form von kleinen. Tröpfchen in der wäßrigen Phase emulgiert werden. Trotz des Zusatzes von Gummi arabicum als Stabilisator besteht die Gefahr, daß vor allem bei Anwesenheit von Puffersalzen sich die Emulsion schon während der Reaktion verändert. Die Aufbewahrung über längere Zeit ist nicht möglich; daher muß die Emulsion vor jeder Untersuchung frisch hergestellt werden, wobei es ziemlich schwierig sein dürfte, selbst bei Verwendung eines Homogenisators jeweils den gleichen Zerteilungsgrad zu erzielen.

Wir haben früher als Substrat Polyoxyäthylensorbitantrioleat (Tween 85) verwendet, weil diese Substanz in Wasser unlöslich ist, sich aber durch kräftiges Aufschütteln in eine Emulsion überführen läßt, die wenigstens für die Dauer der Lipasereaktion hinreichend stabil ist (6). Leider ist Tween 85 nur in für technische Zwecke standardisierter Form erhältlich, so daß die Einstellung dieses Produkts als gleichbleibendes Substrat für die Lipase auf Schwierigkeiten stößt.

Die Aufgabe, ein Olivenölsubstrat für die Lipasereaktion herzustellen, welches eine einheitliche stabile, möglichst große Oberfläche besitzt, um einen optimalen Kontakt zwischen Enzym und Substrat zu schaffen, glauben wir nun auf folgende Weise gelöst zu haben:

Wir bringen das Olivenöl als molekularen Film auf einen fein verteilten inerten Festkörper auf. Als geeignete Trägersubstanz erwies sich hierfür Aerosil. Dabei zeigte sich, daß dieser mit Olivenöl überzogene Träger noch genügend Saugkraft besitzt, um eine bestimmte Menge Serum vollkommen aufzunehmen. Durch diese Maßnahme wird ein idealer Kontakt an den Grenzflächen zwischen Enzymlösung und Substrat hergestellt, und die Reaktion läuft $a b$, obne daß sich die Berührungsflächen in ihrem Verlaufe ändern. Darüber hinaus können diesem Pulver auch die fein verriebenen Puffersalze beigemischt werden, so daß für die Dauer der Reaktion ein konstantes optimales $\mathrm{pH}$ gewähtleistet ist. Die Reaktion selbst läuft somit in einfacher, leicht überschaubarer Weise ab. Durch Mischen des vorgewärmten Substratpulvers mit dem

1) Warenzeichen der Firma Degussa. 
Serum werden durch die Lipase Fettsäuren freigesetzt. Die Zugabe von Chloroform beendet die Lipasewirkung. Die freigesetzten Fettsäuren werden über ihre chloroformlöslichen Kupfersalze in bekannter Weise photometrisch gemessen.

\section{Material und Methoden}

Reagenzien ${ }^{2}$ )

1. Substrat-Puffer-Kapsein

$35 \mathrm{mg}$ Olivenöl, $1,71 \mathrm{mg}$ Natriumcholat, $5,0 \mathrm{mg} \mathrm{Na}{ }_{2} \mathrm{HPO}_{4} \cdot 2 \mathrm{H}_{2} \mathrm{O}$

$0,5 \mathrm{mg} \mathrm{KH} \mathrm{KO}_{4}$ auf $27,8 \mathrm{mg}$ Aerosil

2. Kupfernitratlösung

$130 \mathrm{mmol} / 1 \mathrm{Cu}\left(\mathrm{NO}_{3}\right)_{2} \cdot 3 \mathrm{H}_{2} \mathrm{O}, 500 \mathrm{mmol} / 1$ Triäthanolamin,

$170 \mathrm{mmol} / 1 \mathrm{Natriumchlorid}$

3. Palmitinsäure-Standard

$0,025 \mathrm{mmol} / 1$ Kupfer-Palmitat in Chloroform entsprechend $25 \mathrm{U} / 1$ Lipase

4. Sekundärer Butylalkohol

5. Thiocarbamat-Reagenz in Kapseln zu $20 \mathrm{mg}$

(7 mmol/1 Natrium-diäthyldithiocarbamat)

6. Chloroform p. A.

Das Substrat ist vor Licht geschützt im Kühlschrank aufzubewahren. Die Thiocarbamat-Gebrauchslösung wird auf folgende Weise hergestellt: Der Inhalt einer Kapsel wird in $20 \mathrm{ml}$ sek. Butylalkohol unter Umschwenken gelöst. Die ungelösten Füllstoffe werden nach $10 \mathrm{~min}$ abfiltriert. Diese Lösung ist bei Aufbewahrung im Kühlschrank 14 Tage haltbar.

\section{Arbeitsvorschrift:}

Der Inhalt einer Substratkapsel wird in ein Zentrifugenglas gegeben und darin $5 \mathrm{~min}$ bei $37^{\circ} \mathrm{C}$ im Wasserbad vorgewärmt. Auf das Substratpulver gibt man $0,20 \mathrm{ml}$ Serum und läßt das breiige Gemisch genau $20 \mathrm{~min}$ bei $37^{\circ} \mathrm{C}$ inkubieren. Während dieser Zeit setzt man den Serumleerwert an, indem man $0,20 \mathrm{ml}$ Serum mit 4,0 $\mathrm{ml}$ Chloroform und $1,0 \mathrm{ml} \mathrm{Kupfernitratlösung} \mathrm{kurz} \mathrm{schüttelt}$ und erst anschließend den Inhalt einer Substratkapsel zugibt. Ein Reagenzienleerwert wird durch Zusammengeben von $4,0 \mathrm{ml}$ Chloroform und $1,0 \mathrm{ml}$ Kupfernitratlösung angesetzt. Nach Ablauf der Inkubationszeit werden auch zur Analyse $4,0 \mathrm{ml}$ Chloroform und $1,0 \mathrm{ml}$ Kupfernitratlösung gegeben. Alle drei Ansätze werden 5 min kräftig geșchüttelt und dann zentrifugiert. Der wäßr. Uberstand wird abgesaugt. Von der Chloroformphase wird jerreils $1,0 \mathrm{ml}$ vorsichtig (keine Verunreinigung durch Kupferlösung!) abgenommen und mit je $1,5 \mathrm{ml}$ Thiocarbamatlösung versetzt. Für den Standardwert wird $1,0 \mathrm{ml}$ Standardlösung mit $1,5 \mathrm{ml}$ Thiocarbamatlösung gemischt. Die Ansätze von Analyse, Standard und Serumleerwert werden bei $420-460$ $(\mathrm{Hg} 436) \mathrm{nm}$ gegen den Leerwert gemessen. Können die Lösungen nicht sofort gemessen werden, sind die Gefäße wegen der Gefahr des Verdunstens von Chloroform gut zu verschließen. Die Farbe ist mindestens eine Stunde stabil.

Berechnung

$$
\frac{E_{\text {Analyse }}-E_{\text {Serum-Leerwert }}}{E_{\text {Standard }}} \cdot 25=U / 1 \text { Lipase. }
$$

\section{Diskussion}

1. In der vorstehenden Versuchsanordnung ist als Einheit (U) diejenige Lipasemenge definiert, die bei $\mathrm{pH} 8$ und einer Temperatur von $37^{\circ} \mathrm{C}$ ein Mikromol freie Fettsäuren pro Minute freisetzt.

2. Die Abhängigkeit der Lipaseaktivität von der Inkubationstemperatur ist in Abbildung 1 wiedergegeben.

2) Mit Ausnahme von Chloroform enthalten in Haurytest ,LipaseN“, Dr. H. Haury, Chemische Fabrik, 8 München 40, Postfach 400806.

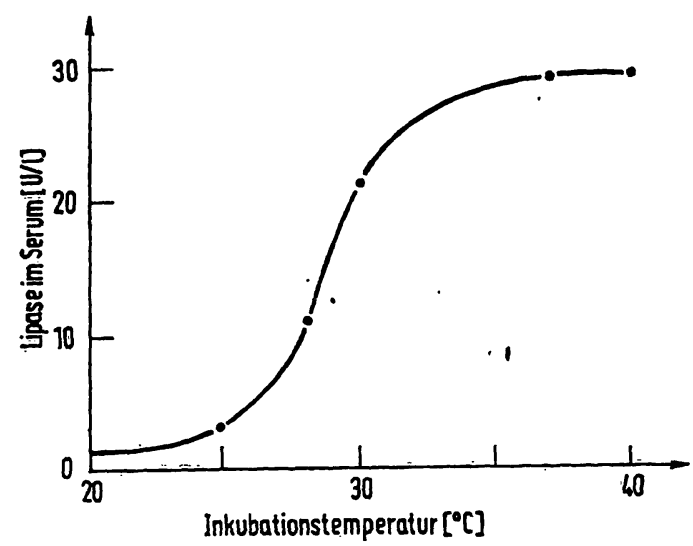

Abb. 1

Abhängigkeit der Lipase-Aktivität von der Reaktionstemperatur

Dabei zeigt sich beim Vergleich mit der Aktivität bei $37^{\circ} \mathrm{C}$, daß bei $25^{\circ} \mathrm{C}$ etwa nur der zehnte Teil an Fettsäuren pro Minute freigesetzt wird. Wir haben uns daher entschlossen, die Temperatur von $37^{\circ} \mathrm{C} \cdot \mathrm{im}$ Interesse einer höheren Genauigkeit vorzuschlagen, wenn wir auch dadurch von den Richtlinien der Enzymkommission der Deutschen Gesellschaft für klinische Chemie abweichen. Für die Temperatur von $25^{\circ} \mathrm{C}$ spricht einzig der Umstand, daß bei kinetischen Tests, bei denen die Extinktion jede Minute im Photometer abgelesen wird, diese Temperatur leichter konstant gehalten werden kann. Bei unserer Methode handelt es sich jedoch um eine sogenannte 2-Punkt-Kinetik, bei der die Fermentreaktion nach einer bestimmten Zeit abgebrochen wird und bei der die Temperatur während des Meßvorganges beliebig sein kann (wenn sie nur für alle Proben gleich ist).

3. Bei der Auswahl des Trägers war zu prüfen, ob die durch die Fermentreaktion freigesetzten Fettsäuren vollständig in die Chloroformphase übergehen. Während alkalische Träger wie Aluminiumoxid die Fettsäuren zurückhalten, konnte bei der Extraktion der Fettsäưren in Anwesenheit von Aerosil nachgewiesen werden, daß diese vollständig erfaßt werden (Abb. 2).

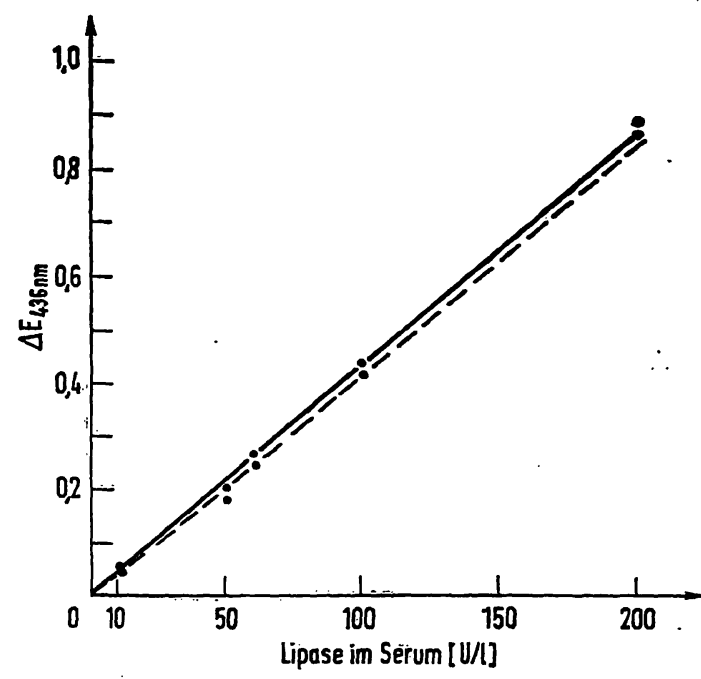

$A b \dot{b}: 2$

Extraktion der freien Fettsäuren aus Olivenöl mit (๑-) und ohne $(0-\ldots)$ Aerosil 


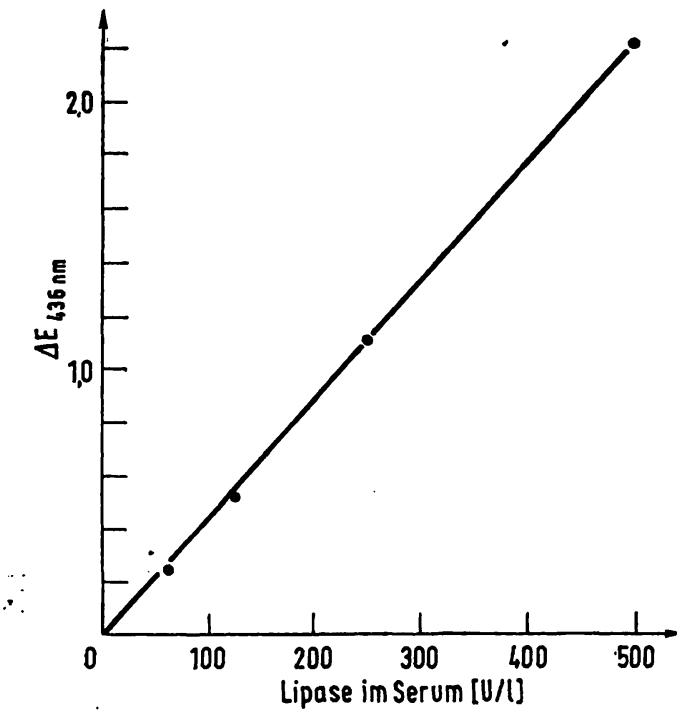

Abb. 3

Verlauf der Eichkurve der beschriebenen photometrischen Lipasebestimmung

4. Die Wahl der eingesetzten Serummengen und der Inkubationszeit war so $z u$ treffen, daß einerseits eine genügend große Menge an Fettsäuren freigesetzt wird, um auch bei niedrigen Konzentrationen eine ausreichende Anzeige zu bekommen, andererseits sollten auch bei hohen Konzentrationen die Werte auf einer Eichgeraden abzulesen sein. Der Einsatz von $0,2 \mathrm{ml}$ Serum und eine Inkubationszeit von $20 \mathrm{~min}$ wird diesen Anforderungen gerecht. Abbildung 3 zeigt die entsprechende Eichkurve, die -bis über 500 U/1 geradlinig verläuft, wobei hier die oberste Grenze durch die Ablesemöglichkeit am Photometer gegeben ist. Bei Werten über $500 \mathrm{U} / 1$ ist die Bestimmung mit $0,1 \mathrm{ml}$ Serum zu wiederholen.

5. Die beschriebene Methode wurde auch mit der titrimetrischen Methode von G. NäHER (7) verglichen. Bei dieser Methode wird ähnlich wie bei der Methode von W. RICK (1) die Freisetzung der Fettsäuren während der ersten Minuten der Lipasereaktion kontinuierlich titrimetrisch verfolgt. Dabei wird unter Stickstoffatmosphäre in einem Anșatz von $1,0 \mathrm{ml}$ Serum und $10 \mathrm{ml}$ Olivenölemulsion unter Zusatz von Desoxycholat und Wasser, ein $\mathrm{pH}$ von 9,0 eingestellt und dieser $\mathrm{pH}$-Wert durch laufende Zugabe von $0,01 \mathrm{~mol} / 1 \mathrm{NaOH}$ während 4 min konstant gehalten. Der Verbrauch der Natronlauge wird als Maßß für die durch die Lipase freigesetzten Fettsäuren betrachtet und zur Aktivitätsberechnung verwendet.

Diese titrimetrische Methode benötigt neben einem

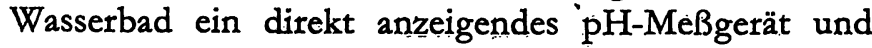
unbedingt eine Kolbenbürette, um die Natronlauge fein genug dosieren zu können. (Übliche Mikrobüretten mit einer Unterteilung von $0,05 \mathrm{ml}$ genügen nicht, da der Verbrauch von $0,05 \mathrm{ml}$ Natronlauge pro Minute schon $125 \mathrm{U} / \mathrm{l}$ Serum entspricht.) Außerdem ist ein Magnetrührer, eine Stickstoffflasche und ein Mixgerät zur Herstellung des Substrats notwendig. Die Ergebnisse dieses Vergleichs bei 14 Seren sind in Abbildung 4

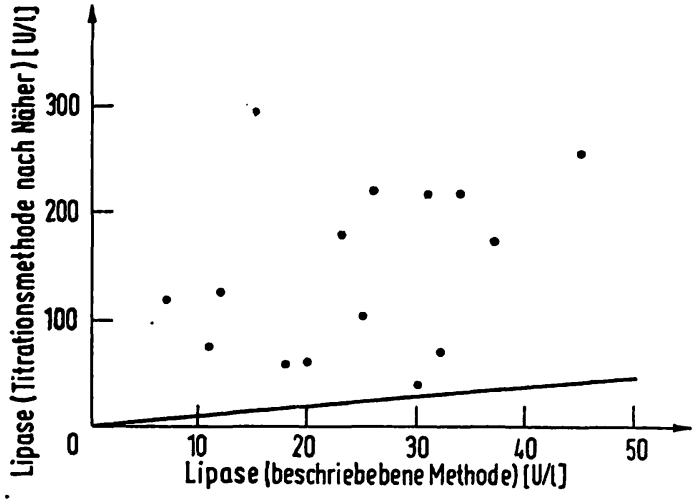

Abb. 4

Kọrelation der titrimetrischen Lipase-Bestimmung mit der beschriebenen Methode

dargestellt. Dabei zeigt sich, daß die photometrisch gemessenen Aktivitätseinheiten immer niedriger liegen als die titrimetrisch bestimmten. Auch besteht kein konstantes Verhältnis zwischen den Wertepaaren. Der Quotient schwankt zwischen 1,33 und 17,14 (Mittel 6,25). Nun könnte man versucht sein, die Ursache dieses Unterschieds in der neuen Substratzubereitung zu suchen.

Um diese Frage zu klären, haben wir bei einer Reihe von Seren unter Verwendung des emulgierten Olivenöls (nach NäHER) den Zuwachs der freien Fettsäuren als Folge der Lipasereaktion sowohl titrimetrisch als auch photometrisch bestimmt. $\mathrm{Da}$ das Olivenöl ein Glycerinester verschiedener hochmolekularer Fettsäuren ist, können dabei nur Fettsäuren mit einer 'Kettenlänge über 10 Kohlenstoffatomen freigesetzt werden. Es dürfte also zwischen den beiden Bestimmungsmethoden kein Unterschied auftreten, wenn bei der Titration nur die durch die Lipasereaktion freigesetzten Fettsäuren titriert werden. Dies ist aber keineswegs der Fall. Im Gegensatz zu den Angaben von ScHMIDT et al. (8) finden wir durchwegs, daß titrimetrisch mehr Protonen neutralisiert werden, als den photometrisch erfaßten Fettsäuren entspricht (Tab. 1). Da die photometrische Fettsäurebestimmungsmethode mehrfach (zu-

Tab. 1

Zunahme der durch die Lipasereaktion freigesetzten Fettsäuren unter Verwendung des gleichen Substrats: Vergleich zwischen Titration und photometrischer Messung im Serum

\begin{tabular}{rccc}
\hline $\begin{array}{c}\text { Serum } \\
\text { Nr. }\end{array}$ & $\begin{array}{c}\text { Titration } \\
\mu \text { mol/min } \cdot 1\end{array}$ & $\begin{array}{c}\text { Photometr. } \\
\text { Messung } \\
\mu \text { mol/min } \cdot 1\end{array}$ & $\begin{array}{c}\text { Titration/ } \\
\text { photometr. } \\
\text { Messung }\end{array}$ \\
\hline 1 & 252 & 42 & 6,0 \\
2 & 945 & 121 & 7.8 \\
3 & 224 & 31 & 7,2 \\
4 & 295 & 44 & 6,7 \\
5 & 605 & 114 & 5,3 \\
6 & 1060 & 317 & 3,3 \\
7 & 2116 & 641 & 3,3 \\
8 & 635 & 78 & 8,1 \\
9 & 376 & 56 & 6,7 \\
10 & 110 & 19 & 5,8 \\
\hline
\end{tabular}


letzt von P. DietrerLe et al. (9)) auf ihre Ubereinstimmung $^{3}$ ) mit der titrimetrischen Methode überprüft wurde, zwingt dieses Ergebnis .zu dem Schluß, daß bei der titrimetrischen Lipase-Methode Fettsäuren erfaßt werden, die nicht durch die Lipasereaktion freigesetzt wurden, sondern anderen nebenher verlaufenden Reaktionen entstammen müssen. $\mathrm{Ob}$ es sich bei dieser Nebenreaktion um die von PILz et al. (10) angeführte Reaktion der Lipoproteidlipase handelt, die als Endprodukt Essigsäure erzeugt, haben wir nicht untersucht, jedoch können wir uns seiner Aussage, daß „die titrimetrische Methode für eine exakte Lipasebestimmung ausscheidet" aufgrund unserer eigenen Untersuchungen anschließen.

6. Für die beschriebene und gegen die titrimetrische Methode sprechen auch noch eine Reihe von praktischen Gründen. Der apparative Aufwand ist bei letzterer so groß, daß nur wenige Laboratorien in der Lage sind, sie durchzuführen, während die hier vorgeschlagene Methode von jedem normal eingerichteten Routinelaboratorium leicht durchgeführt werden kann. Trotz der längeren Inkubationszeit ist schon bei Durchführung einer Doppelbestimmung der Zeit- und Arbeitsaufwand 'für die photometrische Bestimmung günstiger. Bei dieser können außerdem bis zu $8 \mathrm{Be}-$ stimmungen einschließlich Serumleerwert gleichzeitig durchgeführt werden. Auch beim Präzisionsvergleich schneidet die photometrische Methode weit besser ab. Wir haben bei 20 Bestimmungen in der Serie bei einem Serum der Aktivität von $75 \mathrm{U} / \mathrm{l}$ eine relative Standardabweichung (=Variationskoeffizient) von $\pm 2,74 \%$ gefunden; den entsprechenden Wert für die titrimetrische Methode gibt NäHER mit $\pm 9,7 \%$ an.

3) Wir haben uns davon überzeugt, daß bei Verwendung eines von uns entwickelten Horizontalschüttlers die Schüttelzeit von 5 min zur quantitativen Extraktion der Fettsäuren ausreicht.

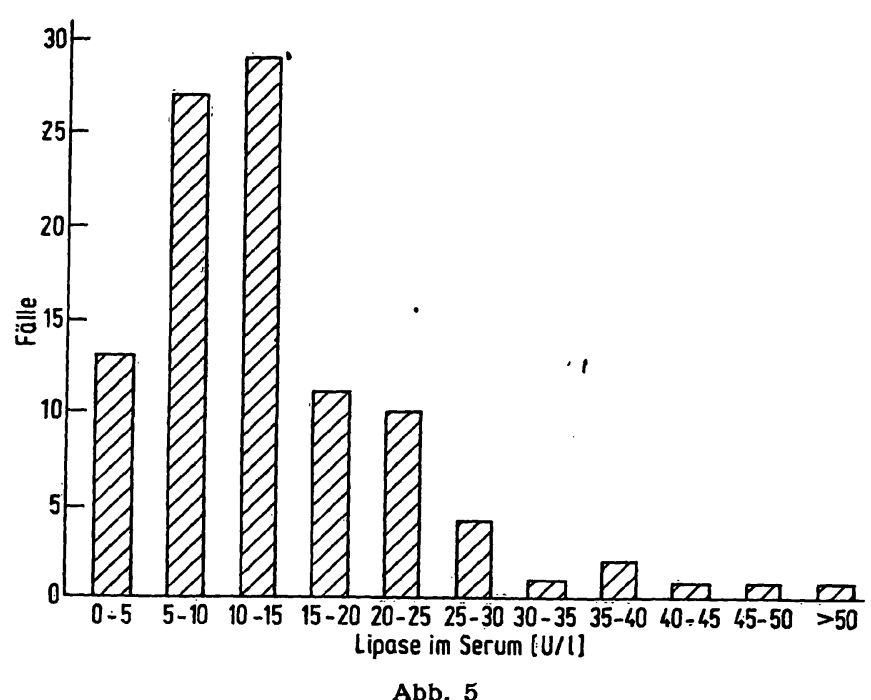

Normalverteilung bei der beschriebenen Lipase-Bestimmungsmethode
(100 Fälle)

7. Zur Ermittlung des Normalbereichs wurden 100 Seren untersucht. Bei diesen Seren handelt es sich um Personen ohne pankreatitische Anamnese. Zur Sicherung wurde von denselben Seren auch die $\alpha$-Amylase bestimmt, die in keinem Fall einen pathologischen Wert zeigte. Die Verteilung der Lipasewerte ist in Abbildung 5 wiedergegeben. Aufgrund der statistischen Auswertung des Untersuchungsmaterials möchten wir für unsere Methode folgende Normalwerte vorgeschlagen:

$$
\begin{aligned}
& \text { 2-40 U/1 Serum normal } \\
& \text { ab } 41 \text { U/1 Serum pathologisch }
\end{aligned}
$$

Wir sind uns bewußt, daß bei weiterer klinischer Erprobung eine geringfügige Änderung dieser Normalwerte erfolgen könnte.

Für die sorgfältige technische Durchführung der Versuche danken wir Herrn R. WILDGRuber und Frl. J. MAYr.

\section{Literatur}

1. RICK, W. (1969), diese Z. 7, 530-539. - 2. KRISCH, K. (1963), Biochem. Z. 337, 546-573. - 3. TIETZ, N. W. \& FIERECK, E. A. (1966), Clin. Chim. Acta 13, 352-358. - 4. WeBER, H. (1965), Deut. Med. Wochenschr. 90, 1170-1174. - 5. Duncombe, W. C. (1963), Biochem. J. 88, 7. - 6. FRIED, R. \& HoEfLMAYY, J. (1969), Therap. Gegenwart 108, 1788-1798. - 7. Näher, G. (1970), in Methoden der enzymatischen Analyse (BERGMEYER, H. U.,
Hrsg.) 2. Aufl. Bd. 2, S. 781-786, Verlag Chemie, Weinheim/ Bergstr. - 8. Schmidt, F. H., StORK, H. \& v. DAHL, K. (197.0), in Methoden der enzymatischen Analyse (BERGMEYER, H. U., Hrsg.) 2. Aufl. Bd. 2, S. 786-791, Verlag Chemie, Weinheim/ Bergstr. - 9. DieterLe, P., WülfERT-HeLDRICh, C., HENNER, J. \& Schwarz, K. (1968), diese Z. 6, 153-155. - 10. Priz, W., HörLEIN, H. \& JohanN, J. (1970), diese Z. 8, 85-91.

Dr. rer. nat. Fried und Dr. med. J. Hoeflmayr 8 München 40

Schleißheimer Str. 343 